\title{
EXPERIENCIAS INTERGENERACIONALES SOBRE ENCIERROS: PASADOS, PRESENTES Y FUTUROS. DETONANTES Y REFLEXIONES EN CLAVE BIOGRÁFICA TRAS LA PANDEMIA DE SARS-COV-2
}

\author{
PAZ VALENZUELA REBOLLEDO ${ }^{1}$ \\ GABRIELA RUBILAR ${ }^{2}$ \\ ALEX MANQUILEPE ${ }^{3}$ \\ LESLY TORRES ${ }^{4}$ \\ CAMILA PERALTA ${ }^{5}$ \\ JOHANNA ARANCIBIA ${ }^{6}$ \\ JUAN GONZÁLEZ ${ }^{7}$ \\ VANESSA SOTO ${ }^{8}$ \\ JOSEPH STRAUSS ${ }^{9}$
}

\section{RESUMEN}

Este artículo analiza narrativas de encierro de un grupo de personas que tematizan distintas experiencias de clausura en sus trayectorias biográficas. Estas narrativas fueron construidas a partir de autoentrevistas, realizadas en el contexto de la crisis sociopolítico-sanitaria que afecta al mundo tras la declaración de pandemia por SARS-CoV-2. A partir de la invitación a contar una experiencia de encierro del pasado, del presente e imaginarios futuros, se exploran en clave temporal las vivencias de distintas generaciones sobre sus encierros y se promueve una reflexividad acerca de los procesos de crisis y las vivencias que estos adquieren para las generaciones jóvenes.

PALABRAS CLAVE: NARRATIVAS, CONTEXTOS DE CRISIS, JUVENTUDES.

\footnotetext{
${ }^{1}$ Trabajadora Social Universidad de Chile, integrante del Núcleo de estudios Interdisciplinarios en Trabajo Social, personal técnico proyecto Fondecyt Regular 1190257. Correo electrónico: paz.valenzuela@ug.uchile.cl

2 Trabajadora Social de la Universidad Católica, integrante del Núcleo de estudios Interdisciplinarios en Trabajo Social, investigadora principal Fondecyt Regular 1190257. Correo electrónico: grubilar@uchile.cl

${ }^{3}$ Estudiante Trabajo Social Universidad de Chile, integrante del Núcleo de estudios Interdisciplinarios en Trabajo Social. Correo electrónico: alex.manquileper@ug.uchile.cl

${ }^{4}$ Estudiante Trabajo Social Universidad de Chile, integrante del Núcleo de estudios Interdisciplinarios en Trabajo Social.

Correo electrónico: lesly.torres@ug.uchile.cl

5 Socióloga Universidad Diego Portales, personal técnico Fondecyt Regular 1190257. Correo electrónico: camila.peralta@mail.udp.cl

6 Asistente social ICE Universidad de Chile, tesista Fondecyt Regular 1190257. Correo electrónico: johanna.arancibia@uchile.cl

7 Trabajador Social Universidad de Chile, tesista del proyecto Fondecyt Regular 1190257. Correo electrónico: juangonzalez@ug.uchile.cl

${ }^{8}$ Estudiante Trabajo Social Universidad de Chile, integrante del Núcleo de Estudios Interdisciplinarios en Trabajo Social. Correo electrónico: vanessa.soto@ug.uchile.cl

9 Trabajador Social Universidad Católica, tesista del proyecto Fondecyt Regular 1190257. Correo electrónico: jastrauss@uc.cl
} 


\title{
EXPERIÊNCIAS INTERGERACIONAIS SOBRE CONFINAMENTOS: PASSADOS, PRESENTES E FUTUROS. DETONANTES E REFLEXÕES BIOGRÁFICAS APÓS A PANDEMIA DE SARS-COV-2
}

\begin{abstract}
RESUMO
Este artigo analisa narrativas de confinamento de um grupo de pessoas que tematizam diferentes experiências de fechamento em suas trajetórias biográficas. Estas narrativas foram construídas a partir de autoentrevistas, conduzidas no contexto da crise social, política e sanitária que afeta o mundo após a declaração da pandemia de SARS-CoV-2. A partir do convite para contar uma experiência de confinamento do passado, do presente e dos imaginários futuros, as experiências de diferentes gerações sobre seus confinamentos são exploradas temporariamente e é promovida uma reflexividade sobre os processos de crise e as vivências que estes adquirem para as gerações jovens.
\end{abstract}

PALAVRAS-CHAVE: NARRATIVAS, CONTEXTOS DE CRISE, JUVENTUDES.

\section{INTERGENERATIONAL LOCKDOWN EXPERIENCES: PAST, PRESENT, AND FUTURE. CATALYSTS AND REFLECTIONS ON A BIOGRAPHICAL KEY AFTER SARS-COV-2 PANDEMIC}

\begin{abstract}
This article analyzes the lockdown narratives of a group of people thematizing different closure experiences in their biographical trajectories. These narratives were built from self-interviews carried out during the socio-political, sanitary crisis context affecting the world after the outbreak of the SARS-CoV-2 pandemic. From the invitation to speak about their past, present, and imaginary future lockdown insights, the different lockdown situations experienced by different generations are temporarily explored, encouraging reflexivity about the processes of crisis and experiences of life for younger generations.
\end{abstract}

KEYWORDS: NARRATIVES, CRISIS CONTEXTS, YOUTHS. 


\section{AgRAdecimientos}

Este artículo ha sido posible gracias al aporte del proyecto ANID/FONDECYT 1190257 Estudio Longitudinal de Trayectorias y Transiciones Investigativas de Trabajadores Sociales chilenos.

\section{INTRODUCCIÓN}

Este artículo surge a partir de un proceso reflexivo desarrollado por un grupo de personas acerca del tiempo y los encierros presentes y pasados, para luego proyectar el futuro. Se inicia en mayo de 2020 en contextos de cuarentena total por Covid-19 y se retoma en abril de 2021, a propósito de nuevas cuarentenas impuestas como medidas de confinamiento ante el avance de la pandemia por SARS-CoV-2 que ha afectado al país y al mundo en los últimos dieciocho meses. El desafío de narrar experiencias de encierro pensadas a partir de autoentrevistas situadas en tres temporalidades fue llevado a cabo por los autores de este trabajo, quienes pertenecen a dos grupos generacionales claramente marcados y a una generación intermedia. Sus reflexiones han sido articuladas en un proceso de análisis que incluye elementos de crisis y transformación, que en el contexto de este artículo ha sido tematizado como triple crisis.

Una de ellas es la crisis sociosanitaria producto de la pandemia, que a la fecha de este artículo ha cobrado más de 35 mil vidas, afectando las dimensiones macro, meso y micro de nuestra sociedad, las condiciones de ser joven y adultojoven en contextos de pandemia. En forma sinérgica, esta crisis ha transformado las ideas sobre el futuro y planteado profundas interrogantes en las trayectorias de quienes se aproximan a la vida adulta o transitan en ella.

Las medidas impuestas en Chile para frenar la pandemia por SARS-CoV2 y sus variantes, incluyendo las últimas cepas descubiertas, implicaron 
inicialmente acciones voluntarias de aislamiento social y restricción de la movilidad, combinadas con medidas de estado de excepción como toque de queda y cancelación de eventos públicos, que ya venían efectuándose desde el estallido social de octubre de 2019, a las que se suman periodos de cuarentena total o parcial para distintas zonas y territorios del país.

Una vez declarada la pandemia, las y los jóvenes en edad escolar y en procesos de formación universitaria se enfrentaron a un proceso gradual de transición a modalidades de enseñanza no presencial que incluyeron clases virtuales y procesos formativos que se trasladan a distintos espacios y formatos y que permanecen hasta el día de hoy. Uno de ellos son las clases sincrónicas, que en el ámbito universitario se realizan semanalmente y donde se sitúan estas narrativas que surgen de un grupo heterogéneo de estudiantes de pregrado y magíster, profesionales recién titulados y personal técnico de un proyecto de Estudios longitudinales de trayectorias y transiciones.

En este contexto formativo se desarrolló el proceso de investigación y análisis que se presenta en este artículo, que se inicia con la pregunta disparadora ¿cuéntame una experiencia de encierro? Que usa el eje del tiempo pasado/presente/futuro para activar un proceso de reflexividad grupal.

La pregunta sobre el encierro que guía este artículo surge cuando se analiza en clave hermenéutica la experiencia de encierro de Goffman (2019[1961]) en Internados y se decide realizar de manera conjunta una práctica de autoentrevista (Appel, 2005; Boufoy-Bastick, 2005; Ellis, Adams y Bochner, 2011) de los propios encierros experimentados por los participantes de este artículo a propósito de las medidas de cuarentena total de mayo de 2020.

Las narrativas de dichos encierros (que fueron denominadas encierros presentes) fueron combinadas con una mirada retrospectiva de encierros pasados, que gatillaron en las y los jóvenes participantes una reflexión sobre el futuro después del Covid-19. Esta reflexión sobre el futuro se desarrolló en dos claves 
temporales: el futuro inmediato proyectado en una temporalidad acotada a un año plazo (mayo de 2021) y un futuro posible a partir de las transformaciones experimentadas tras la pandemia por SARS-CoV-2, claramente inédita para los autores de este trabajo y que no tiene un horizonte temporal acotado.

El análisis del material de las autoentrevistas fue realizado a partir de la conjunción entre la clasificación temporal de las experiencias de encierro narradas por sus protagonistas, así como por la agrupación de las narrativas según el criterio generacional que une y diferencia a los y las participantes. La reflexión sobre los encierros se desarrolla en clave biográfica y con las orientaciones de un proceso de vigilancia epistemológica (Bourdieu y Wacquant, 2005[1992]; Piovani y Muñiz-Terra, 2018), que animó a los participantes a escribir estas narrativas, a reflexionar críticamente sobre ellas, levantando algunas categorías de análisis a partir del diálogo entre estas experiencias de encierro pasadas cuando se era más joven con las experiencias de encierro de otras generaciones, que vivieron otros encierros y/o que los experimentan desde otros referentes.

Este artículo se escribe en el entrecruce de una triple crisis: a) la crisis política que se deja entrever desde octubre de 2019 y que permite los procesos de reforma y cambio constitucional que experimenta el país, enraizados en movimientos previos de hace más de una década (Garcés, 2012); b) la crisis social que es desencadenada por un modelo económico que expulsa y orilla, vulnerabiliza y estigmatiza a las personas que solicitan ayuda o demandan aquello a lo cual se tiene derecho; y c) una crisis sanitaria que refuerza la importancia de contar con decisiones de política universales, modelos de protección amplios y sistemas que brinden oportunidades igualitarias para todos, puesta en evidencia ante los primeros brotes de Covid-19 y que permanece vigente tras dieciocho meses de pandemia.

Esta triple crisis sociopolítico-sanitaria tiene elementos comunes con otras crisis acontecidas en las últimas décadas, donde las y los jóvenes han sido 
sus protagonistas (Hessel, 2011; Garzón, 2011; Thunberg, 2020), demandando la transformación de estructuras y cambios de lógica de procesos largamente asentados, tras la convicción de que Algo va mal (Judt, 2011). Demandas y movilizaciones que también han sido impulsadas por las y los jóvenes en Chile, desde el movimiento pingüino en 2006 que abogaba por la calidad de la educación; el movimiento universitarios por la gratuidad en 2011; el movimiento feminista de 2018 y el sentimiento de indignidad que lleva al estallido social de octubre de 2019 (Araujo, 2019; Rubilar, Santibáñez y Echeverría, 2020; Alé, Duarte y Miranda, 2021), tras quince años de movilizaciones juveniles que nos han llevado a experimentar que es posible pensar en otros futuros y que la suerte no está echada.

\section{NARRATIVAS INDIVIDUALES Y GENERACIONES PARA COMPRENDER LO SOCIAL}

Asistimos a lo que Araujo y Martuccelli (2012) denominan la nueva sensibilidad social, caracterizada por la interrogación de las vivencias individuales con el fin de ponerlas en comprensión con grandes cambios estructurales de un período, sin reducirlas necesariamente a ellas (Martuccelli, 2017: 94). Desde el punto de vista fenomenológico, hay un rescate de la experiencia vivida y este es precisamente el punto de partida de este artículo, que analiza las narrativas de encierro de un grupo de personas y que fueron construidas a partir de un proceso de autoentrevistas.

Esta sensibilidad se hace más visible a partir de la condición social moderna, que se consolida como perspectiva analítica, sostenida en aquellos argumentos que afirman que la comprensión de la vida social se ha organizado en diferentes corrientes a partir de las nociones de civilización, sociedad, clases o Estado-nación, incluyendo la preponderancia del individuo como lugar para comprender y describir las sociedades contemporáneas (Araujo y Martuccelli, 
2012).

En este sentido, la articulación de vivencias individuales, estructuras sociales e inquietudes históricas (Martuccelli, 2015) da lugar a una visión conjunta que estimula una forma particular de imaginación sociológica (Mills,2005[1959]), la cual aborda la experiencia como foco de estudio. Ello no supone profundizar en la interiorización de normas sociales o en el agenciamiento de la acción social, sino más bien reflexionar sobre los modos de regulación cotidiana de los actores en un momento histórico situado (Dubet, 2011).

A partir de las experiencias de los individuos, es posible interpretar el momento que las sociedades están atravesando y cómo, en este marco, los individuos somos capaces de construirnos como sujetos (Araujo y Martuccelli, 2010; Millenaar et al., 2016; Muñiz-Terra y Roberti, 2018). La interpelación a la reflexividad de esta experiencia deviene precisamente de esta tendencia al estudio de los procesos de construcción identitaria, que ha sido seguida por distintas disciplinas que promueven un ejercicio de análisis en esta dirección (Bourdieu y Wacquant, 2005[1992]; Rubilar, 2013 y 2015; Piovani y Muñiz Terra, 2018).

En este sentido, detenernos a observar la reflexividad de los actores permitirá comprender mejor en qué sociedad vivimos, o al menos, «en qué sociedad vivimos desde el punto de vista de los actores que la componen» (Dubet, 2011: 58), opción que seguimos en este trabajo al promover un ejercicio de reflexividad acerca de los encierros.

Asumiendo esta perspectiva para abordar lo social, este artículo se sitúa a su vez desde un enfoque generacional (Miranda, 2016; Bendit y Miranda, 2017) que recoge los modos de comprender y aproximarse a la cuestión de las generaciones y su construcción histórica. Los estudios de juventudes (Duarte, 2005; Aguilera, 2009) suelen ser bastante explícitos en la cuestión de la 
temporalidad y en la construcción de identidades de vidas en tránsito (Jacinto, 2016; Rubilar, Muñiz-Terra y Domínguez, 2019), precisamente porque ponen el foco en las trayectorias y en los itinerarios seguidos por los sujetos en contextos de transformación y cambio.

El contexto en el cual transcurren estas transiciones se convierte entonces en aspectos significativos de esta corriente de investigación, junto con una mayor especificidad de la coyuntura histórica en el estudio de transiciones de vida, las cuales están fuertemente marcadas por «el contexto político, social y económico en el cual transcurren» (Bendit y Miranda, 2017: 29). Categorías como adolescencia o juventudes son concebidas como construcciones sociohistóricas, culturales y relacionales, pues se constituyen como significaciones sociales de sociedades contemporáneas determinadas, en procesos de permanentes cambios (Dávila León, 2004: 85). En palabras de Canales y Duarte (2020), «lo juvenil de las generaciones, que al final es el estudio de las generaciones, del paso del tiempo, y en ese sentido lo juvenil es siempre una modulación de la transición histórica» (Canales y Duarte, 2020: 223).

El estudio de las generaciones desde la formulación teórica de Mannheim (1993[1928]) abre la posibilidad de observar la temporalidad marcada por la colisión entre el tiempo histórico y el tiempo biográfico (Leccardi y Feixa, 2011: 17). Ser parte de una generación implica compartir discontinuidades históricas específicas, compartir el cambio y ser partícipes de esa parte del proceso histórico que nos ha tocado vivir. Ejemplificado por Bendit y Miranda (2017):

(...) ser parte de una generación que atraviesa su inserción laboral durante años de crisis y estancamiento económico implica contar con un rango menor de oportunidades de acumular experiencias significativas durante la construcción de la trayectoria laboral, con importantes efectos en la posición ocupacional de largo plazo. Más aún, en los últimos años y frente al contexto social provocado por la crisis de 2008, los actuales estudios europeos comenzaron a plantear la emergencia de una generación marcada o una generación «precaria». (Roberts, 2012 en Bendit y Miranda, 2017: 30) 
Lo intergeneracional en este trabajo se encuentra contenido en la posibilidad de diálogo y contraste de los participantes de este estudio, que pertenecen a lo menos a dos generaciones diferenciadas, cuyos entrecruces biográficos están marcados por agitaciones comunes con significaciones distintas que son compartidas por quienes se ubican entre generaciones.

Mannheim introduce la idea de que la duración de la generación se determina según distintas concepciones. En las aproximaciones que él denomina racionalistas-cuantitativas parecen predominar aquellas perspectivas que sitúan a las generaciones en rangos de treinta años, mientras que las aproximaciones románticas o cualitativas enfatizan las diferencias en lo experiencial, transformando la distancia de la generación en un «tiempo interior vivenciable, y la contemporaneidad de la generación en un ser interior idénticamente determinado» (1993[1928]: 199). Aporta además una tercera alternativa, que da cuenta de una relación de tensión dinámica, donde «dichas intenciones básicas están presentes en los espacios sociales como principios formativos durables (aun cuando se transformen constantemente), más allá de los cambios generacionales» (1993 [1928]: 235).

Tomando en cuenta lo anterior, en este artículo recurrimos a esta noción dinámica de generación que, si bien considera algunas distinciones cronológicas para diferenciar una de otra, se centra más bien en una experiencia compartida, que conlleva el haber vivido-experiencias de encierro en un mismo «tiempo vivencial» (Pinder en Mannheim, 1993 [1928]: 200). Esto posibilita, no solo diferenciar a una generación de otra, sino establecer puntos de enlace entre ellas, de ahí el énfasis intergeneracional, en la producción de conocimiento sobre los procesos de crisis que estamos viviendo como humanidad y en la forma como estos son experimentados por dos generaciones claramente diferenciadas: los jóvenes, los mayores y una generación intermedia. 
Esto posibilita, no solo diferenciar a una generación de otra, sino establecer puntos de enlace entre ellas, lo que da cuenta de una conexión intergeneracional, que es lo que permite explicar la existencia de testimonios ubicados entre «medio-generaciones» (Marsal, 1979: 17).

Esta idea de lo intergeneracional, que incluye a la media generación, se relaciona con la noción de agitación generacional tomada de Mannheim, que se resignifica en este trabajo con los aportes de Bajtin (1993[1979]) y su mirada sobre la temporalidad situada «que se produce por distintas voces que no se confunden, ni se sintetizan, sino que habitan en el presente en una polifonía» (en Cornejo et al., 2011: 62), aspectos que retomaremos en el siguiente apartado que explica las opciones metodológicas seguidas en esta investigación.

\section{DELIMITACIONES METODOLÓGICAS}

Este artículo se construye siguiendo las directrices del enfoque biográfico-narrativo (Bertaux, 1990[1980] y 2005[1997]), perspectiva teóricometodológica escogida para desarrollar el proyecto de investigación que aglutina a los autores de este trabajo, quienes al mismo tiempo son los participantes del estudio.

Se inicia con un proceso de autoentrevistas (Valles y Baer, 2005; Appel, 2005; Boufoy-Bastick, 2005; Ellis, Adams y Bochner, 2011; Rubilar, 2015) desarrolladas en dos momentos del tiempo: mayo de 2020 y abril de 2021, en el contexto de un curso de formación universitaria, mientras se desarrollan acciones de docencia no presencial producto de medidas de cuarentena total. Las narraciones se construyen a partir de una pregunta disparadora que invita a los participantes «a contar experiencias» (Rubilar, 2013) en este encierro ocasionado como medida sanitaria ante la pandemia por SARS-CoV-2 y experiencias pasadas con clausuras. 
El primer momento de autoentrevistas se realizó en mayo de 2020 con cuatro participantes. Estas mismas personas volvieron a realizar una entrevista en abril de 2021, esta vez con cinco estudiantes más, quienes escribieron sus experiencias de encierro pasado, presente y futuro.

Estas narrativas fueron producidas de manera individual en textos escritos, que luego fueron compartidos con los demás participantes en lecturas en voz alta en sesiones de trabajo semanal realizadas vía Zoom, lo que permitió llevar a cabo un ejercicio de reflexión grupal acerca de las experiencias. El análisis siguió la misma clave temporal: pasado, presente y futuro. Se toman como referente para la construcción de narrativas las aportaciones de Valles y Baer (2005), Biblia y Bonet-Martí (2009), Galaz y Rubilar (2019).

Las autoentrevistas fueron realizadas por las y los nueve autores de este artículo, quienes tienen entre 20 y 48 años de edad. Para el análisis de estas experiencias de encierro, se agruparon a los participantes por edad y experiencias biográficas similares, siguiendo la idea de dos generaciones y una generación intermedia, en el sentido propuesto por Marsal (1979). De esta forma, se configuraron tres grupos generacionales: uno llamado generación joven con dos participantes menores de 25 años, otro llamado generación adulta con dos participantes mayores de 45 años y una generación intermedia integrada por participantes cuyas edades fluctúan entre 25 a 32 años, que corresponde a jóvenes en tránsito a la adultez.

En este sentido, los grupos generacionales se relacionan con una noción de juventud en tanto experiencia vivida y no como un concepto necesariamente anclado a la edad actual, como ocurre por ejemplo con episodios pasados, cuando las y los participantes eran adolescentes narrados por quienes hoy son adultos o transitan a la adultez.

Las narraciones escritas y producidas en 2020 fueron complementadas un año después por otras narraciones que se producen tras la continuidad de la crisis 
sociopolítico-sanitaria que afecta al país y al mundo, lo que permite imprimir en este trabajo una perspectiva longitudinal para observar el movimiento entre tiempos y generaciones.

De la integración de los relatos se obtuvieron nueve narrativas pasadas, nueve narrativas presentes y nueve narrativas futuras a largo plazo, con con narrativas futuras de un año después, dado que esta última dimensión dio origen a varias narrativas futuras dependiendo del momento de la autoentrevista y la posibilidad de escribir más de un futuro si él o la participante se autoentrevistó en 2020 y 2021 (dando origen, en este caso, a una narrativa futura a y b).

Los resultados que presentamos a continuación analizan el futuro venidero a partir de varios acontecimientos que están por venir, aspecto que ya había sido abordado, aunque de manera incipiente, en Rubilar, Muñiz-Terra y Domínguez (2019) para el caso de jóvenes de educación técnico-profesional.

Las narrativas producidas en estos dos momentos de autoentrevista temporales distintos (2020 y 2021) fueron analizadas de manera conjunta en sesiones telemáticas, a partir de códigos abiertos propuestos por los y las participantes que emergen de su primera revisión y luego de categorías agrupadas por el momento del tiempo al cual interpelan, dando origen a narrativas de pasados, presentes y futuros. La autoría de las narraciones recopiladas en estas autoentrevistas sigue los planteamientos de Beverley (2013[1994]) sobre autoridad narrativa, por lo que los autores de este trabajo son también los participantes de la investigación.

En las sesiones telemáticas se obtuvo el consentimiento de las y los participantes para incluir fragmentos de sus narrativas en la sección de análisis. El texto producido en este artículo ha sido consensuado en las sesiones de trabajo conjuntas. 


\section{RESULTADOS Y ANÁLISIS}

\subsection{LA EXPERIENCIA DE ENCIERRO TRAS EL COVID-19 O SARS-COV-2}

Frente a la propuesta de escribir sobre algún recuerdo o experiencia relacionada con el encierro en clave temporal, las sensibilidades y emociones frente al encierro por SARS-CoV-2 son tópicos identificados en todas las autoentrevistas de las distintas generaciones. Las restricciones sanitarias asociadas a la pandemia, específicamente a los extensos confinamientos, han generado sentimientos vinculados a la fatiga emocional y el cansancio, así como la desesperanza y la resignación frente a la crisis sociopolítico-sanitaria.

Los participantes de este artículo manifestaron sentir una sensación de agotamiento y una alta extenuación emocional vinculada a los períodos extensos de confinamiento, que en el periodo 2020 se extendieron hasta dieciséis semanas y en 2021 se ajustan hasta doce actuales, junto con una intermitente sensación de soledad, así, el «estar encerrada agobia y eso lo puedo decir con total certeza tras la experiencia del año pasado» (autoentrevista presente, participante 4, generación adulta).

En las autoentrevistas se expresa cansancio, consecuencia del esfuerzo de habituarse a las medidas de restricción mencionadas:

Los periodos en soledad me han afectado y he tenido que volver a compartir ese abrumador y pequeño espacio conmigo mismo, en un comienzo solicitando permisos temporales solo para caminar. (Autoentrevista presente, participante 9, generación intermedia).

El agobio y la soledad percibidos, vinculados al encierro y al aislamiento, ya han sido registrados en estudios que han querido profundizar sobre los sentimientos que genera la crisis sanitaria y el impacto en la salud mental (Johnson, Saletti-Cuesta y Tumas, 2020; Rodríguez Quiroga de Pereira et al., 2020; Barros et al., 2020). Esto sumado a las perspectivas que plantean que el neoliberalismo en Chile ha trascendido el plano económico para adentrarse en las 
subjetividades, las formas de entender la sociedad y el sufrimiento psíquico de los individuos, expresado en los altos índices de depresión y malestar individual y colectivo (Cea-Madrid y López-Pismante, 2014; González, 2020), malestar que se amplifica cuando se acopla a la desafección por la rutina del confinamiento doméstico y las pautas que marcan la cotidianidad. Junto con expresar cansancio vinculado al encierrom que ya no es solo físico, sino que también psicológico y social, las sensibilidades asociadas al encierro pandémico están ligadas a sentimientos de resignación y desesperanza, puesto que algunos participantes enfatizan en que estos acontecimientos de alta incertidumbre son a su vez una espera desalentadora (Jacinto, 2016; Auyero, 2013), debido a la certeza de que este nuevo escenario es más complejo de lo que creíamos en el proceso de autoentrevistas de 2020. Así queda en evidencia en dos narrativas recogidas en 2021:

El factor cansancio está muy vinculado al encierro mental, a veces por muchas ganas que tenga de salirme un poco de la rutina, no se puede, principalmente porque me desorganiza todo lo que con mucho esfuerzo me he podido organizar. (Autoentrevista presente, participante 2, generación joven).

Este encierro me parece más desesperanzador, sobre todo porque el año pasado tenía la esperanza de la ignorancia, pero este año solo tenemos confirmaciones de realidad y la seguridad de que cada vez será más duro salir de esto cuerdos y amorosos. (Autoentrevista presente, participante 1, generación intermedia).

Con los fragmentos anteriores se puede afirmar que, pese a que los participantes de este proyecto pertenecen a distintas generaciones, emergen elementos comunes que dan cuenta de experiencias de encierro en el pasado que coinciden con la visión acerca de lo juvenil comentadas en el punto anterior y los procesos de individuación presentes en las transiciones de la adolescencia a la juventud y/o desde la juventud a la adultez. 


\subsection{LO VIVIDO Y LO NO VIVIDO EN EL ENCIERRO PANDÉMICO}

La confirmación de una realidad desalentadora se instala a nivel intergeneracional junto con las «experiencias vividas compartidas» dentro del período de confinamientos sociales, experiencias con las que justamente se establece un enlace entre las diversas biografías y la colisión con los procesos sociohistóricos de crisis. Lo vivido se sitúa como distintas experiencias que se movilizan entre la agencia y la reflexividad, las cuales van entre la habituación al contexto de encierro, la adscripción a estrategias de regulación y autocuidado a nivel individual, así como algunas consideraciones de las juventudes a problematizar aspectos estructurales que están condicionando las trayectorias de vida.

Goffman (2019[1961]) entiende que la vida de quien está encerrado pasa por un ajuste primario, donde se incorporan pautas y reglas; y por un ajuste secundario que lleva a satisfacer posteriormente ciertas necesidades mediante prácticas que permiten conservar cierto control sobre el medio. Debido a que los confinamientos parciales y totales se extendieron desde 2020 al 2021, los participantes de este artículo expresaron que la experiencia del año pasado permitió tener aprendizajes sobre cómo vivir el encierro y hacer ajustes en el cotidiano, permitiendo sopesar la crisis sociopolítico-sanitaria con regulaciones como la asignación a tiempos destinados a la distribución del tiempo para familia, el trabajo y ocio, así como algunas estrategias de autocuidado:

Me pongo a pensar en todo el tiempo que tuve en algún momento y me hace valorar aún más los momentos en donde una puede ser una misma, descansar si es que así lo quieres, dibujar si es que así lo quieres, tener tiempo de películas y mayor vinculación familiar. (Autoentrevista presente, participante 2, generación joven).

La experiencia del año pasado me permitió programar todo con cierta calma, tener ajustes entre tiempos y momentos, respirar cuando es necesario. Este año, soy una versión preventiva de mí misma. (Autoentrevista presente, participante 1, generación intermedia). 
Afortunadamente ahora hay un tramo para practicar deporte. Durante el año pasado no fue así y tuve que salir al parque sin salvoconducto en varias oportunidades, corriendo el riesgo de que me detuvieran o me multaran, pero la necesidad fue mayor al miedo. (Autoentrevista presente, participante 8 , generación adulta).

Esta resignificación de la imagen del encierro en cuarentena,apunta a lo que Pinto (2020) llama el cuestionamiento sobre cómo se ve y se habita esta nueva cotidianidad, abordando preguntas como «¿cómo se ve quien soy ahora? Y ¿cómo es mi vida dentro de un nuevo escenario normal?» (p. 29).

Esta interrogante sobre cómo es nuestra vida en este nuevo escenario, lo no vivido, está referida a la nostalgia de la vida prepandémica y con ello a las expectativas no cumplidas de lo que viviríamos sin el encierro, por ejemplo, que «producto del confinamiento de fines de marzo, como equipo de trabajo, no pudimos terminar el proyecto en el cual estaba contratado» (autoentrevista presente, participante 3, generación intermedia).

Lo no vivido aparece como una categoría que emerge como enlace de las generaciones jóvenes e intermedias, posiblemente porque ambas generaciones están más remitidas a los procesos de entrada a la etapa de vida adulta, transición vital en la que las aspiraciones y planes para el futuro se configuran por proyectos o por anticipación del futuro (Pais, 2002; Casal, 2002):

Respecto a mi noción de encierro, ahora en el presente, lo asocié instintivamente a momentos y situaciones no experimentadas (...) Por ejemplo, la actividad que estamos haciendo ahora, de escucharnos unos a otros pudo haber sido completamente distinto, quizás en una sala sentados escuchándonos en un círculo o en otro lugar de la universidad, pero eso no pasó, ese momento se perdió y no se va a recuperar. (Autoentrevista presente, participante 6 , generación joven).

\subsection{ESCENARIOS POSIBLES A LAS INCERTIDUMBRES FUTURAS}


La perspectiva temporal permitió a las y los participantes explorar algunas significaciones al tematizar experiencias de encierro en su pasado, observar el presente y plantearse algunos escenarios posibles en el futuro. Estas posibilidades de pensar en clave temporal son propias de los estudios longitudinales y permite distintas aproximaciones sobre el futuro y los planes o proyectos que se concretaron o no, analizando aspiraciones y expectativas de jóvenes, así como los factores que inciden en sus decisiones (Sepúlveda, 2021).

En el perfilamiento de tres escenarios imbricados observamos: a) Transiciones futuras individuales; b) agudización de la crisis sociopolíticosanitaria; y c) anhelos de una profunda transformación social, que coinciden con los procesos sociopolíticos vividos a nivel país.

a) En términos individuales, los y las participantes observan sus propios procesos de individuación (Martuccelli y Araujo, 2012) que, desde una mirada micro, interpelan a su propia biografía y dan cuenta de las dificultades de proyectarse ante un contexto de alta incertidumbre.

Lo observado en este punto da cuenta del carácter específico de una sociedad histórica a escala de los individuos (Araujo y Martuccelli, 2012: 14), considerando dimensiones orientadas a la participación de los y las participantes como actores en un colectivo social e histórico común, donde la experiencia personal se convierte en el criterio central para distinguir vías posibles y aconsejables para decidir sobre desafíos estructurales (Araujo, 2009). Algunos de estos desafíos identificados se relacionan con la adaptación al contexto de encierro en etapas del ciclo vital y sociohistóricas como el desafío de envejecer en Chile, así como la incertidumbre del retorno a la vida presencial:

Tengo una preexistencia a la longevidad (mis abuelos lo atestiguan), por lo que este giro que he dado en el último año es una forma de pensar cómo quiero vivir la (otra) mitad de vida que me queda, de hacer frente al vacío de la soledad y de enfrentar mis propios miedos, como la incertidumbre 
sobre el futuro, la autonomía relativa y las dificultades de llegar a fin de mes. (Autoentrevista futuro-a, participante 4, generación adulta).

Si miro hacia el futuro y me proyecto en un año más, siendo optimista, esperaría recuperar un poco de la vida prepandemia, con la diferencia de que esta vez sea real y no tengamos que «volver al comienzo» una vez más. (Autoentrevista futuro, participante 9, generación intermedia).

Mi noción de encierro en el futuro: no disfrutar la vida como a mí me gusta disfrutarla. (...) aun así, para mí el futuro es algo muy incierto, y prefiero no imaginar o proyectarme mucho en él. (Autoentrevista futuro, participante 6 , generación joven).

En este sentido, estas narrativas sobre transiciones futuras individuales no se desligan de las tramas estructurales. Al contrario, la crisis sociopolítico-sanitaria se exacerbó frente a las desigualdades sociales ya expresadas por colectivos y movimientos en el estallido social, por ejemplo, bajo la condición de hacerse y ser adulto mayor en Chile, remitiendo problemáticas como la dependencia económica, percepciones negativas sobre la vejez, las bajas pensiones en Chile y en general el maltrato estructural de actores e instituciones hacia este grupo (Ortega González, 2018).

b) El segundo escenario posible, referido a la agudización de la crisis sociopolítico-sanitaria, es una versión donde las sensibilidades y emociones del presente pandémico referidas anteriormente son más recrudecidas. En este escenario se observa mayor pesimismo, en tanto las narrativas hacen referencia a estar más encerrados, más desesperanzados y más solos a partir de la extensión de las experiencias no vividas, mencionadas anteriormente. Lo no vivido se visualiza en el futuro como aspiraciones y planes coartados por un nuevo escenario ya establecido, donde «el futuro no es ninguno» (autoentrevista futuro-b, participante 4, generación adulta), pues la promesa del futuro se desvanece.

En esta línea, Boaventura de Souza (2020) aporta que la construcción como ciudadanos requiere de contextos físicos que no pueden ser reemplazados por 
la virtualidad, pese a que las herramientas virtuales han aportado en sostener la comunicación y el relacionamiento con otros en encierro. El aislamiento, que es físico y social, ha aportado en la pérdida — entre otras cosas — de la sociabilización presencial, así como la posibilidad de construir vínculos y espacios palpables donde los y las jóvenes pueden relacionarse (Rivera Vargas y Passerón, 2020: 7). En este contexto, ser jóvenes en un mundo de aislamiento y encierro supone una pérdida de sociabilidad, así lo comenta una entrevistada cuando señala que están:

acostumbrados a no ver a los suyos, no abrazar y no oler, pero nos seguimos viendo y escuchando. (Autoentrevista futuro-a, participante 1, generación intermedia).

Los y las participantes de este artículo ven con escepticismo el futuro, siguiendo la línea de ser parte de una generación marcada o generación «perdida» (Standing, 2013 en Bendit y Miranda, 2017), que da cuenta de efectos que tradicionalmente eran asociados a la desocupación y la precarización laboral, pero que podrían en un futuro estar marcados además por la nueva forma de relacionarnos a partir de los confinamientos, imbricación mencionada anteriormente en relación con las incertidumbres en las transiciones individuales futuras y la sensación de exacerbación de problemáticas sociales mencionadas desde los movimientos estudiantiles, el movimiento feminista o el estallido social. Varias narrativas dan cuenta precisamente de esta dimensión:

Espero que la estructura gubernamental no nos encierre tanto en ámbitos de movilidad y expresión, que si llega a pasar la pandemia no ocurra algo que nos lleve a limitarnos nuevamente al desahogo que se estaba llevando a cabo antes de la pandemia. (Autoentrevista futuro, participante 2, generación joven).

Estamos encerrados y seguiremos encerrados; lo único que está permitido hacer es «trabajar», y hasta por hacer lo único que se puede hacer son capaces de encerrarte. (Autoentrevista futuro, participante 5, generación intermedia). 
Esta realidad orweliana me abruma y creo que lejos de terminar, este es el inicio de una nueva forma de vivir que no quiero y no acepto. Por lo mismo, veo el futuro de manera bastante pesimista, no creo que esto acabe, más bien creo que es un nuevo establishment que se quiere imponer y que la gente está aceptando como forma de sobrevivir. (Autoentrevista futuro, participante 8 , generación adulta).

c) Si bien la agudización de la crisis sociopolítico-sanitaria es un escenario compartido a nivel intergeneracional, el escenario sobre una nueva transformación social está emplazado por los participantes de la generación intermedia, quienes identifican un futuro que debiese estar marcado por el abordaje de las desigualdades sociales y nuevas formas de habitar el mundo. En este sentido, este escenario va en sintonía con la ruptura del imaginario simplista que se ha intentado construir sobre una juventud individualista y apática (Alé, Duarte y Miranda, 2021: 12). El encierro en perspectiva de futuro no se tematiza desligando a las desigualdades sociales, al contrario, están arraigadas en su problematización. El extracto de una narrativa reafirma este punto, al señalar:

Me gustaría un cambio radical de formas de habitar el mundo. No quiero decir con esto que en una nueva forma de vivir no existan otras desigualdades, pero serían estas tratadas como fenómenos que deben ser atendidos con efectividad y urgencia. Donde el reconocimiento y redistribución sean pilares de cómo nos organizaremos para intervenir en estos fenómenos. (Autoentrevista futuro, participante 5, generación intermedia).

Siguiendo a Alé, Duarte y Miranda (2021), los y las jóvenes no viven en otro mundo, son conscientes del vínculo generacional a través de las historias familiares, pues han vivido junto a sus madres, abuelas, abuelos, padres y abuelos, la experiencia de agotamiento, de exclusión, de encierro y de expulsión. La revuelta de octubre, liderada por las generaciones nuevas, nació bajo en el neoliberalismo y a partir de las memorias de la pobreza y el castigo estamental como norma; los nuevos, en cambio, no temen a los estigmas ni están dispuestos a mantenerlos (Alé, Duarte y Miranda, 2021: 20). 
Me gustaría un nuevo Chile, un Chile como el que entrega vacunas a toda la población. ¿Será eso posible? Que el Chile que vacuna pague también sueldos igualitarios, que entregue salud, vivienda, educación para todes en la misma calidad, a tiempo y sin exclusiones. (Autoentrevista futurob, participante 1 , generación intermedia).

Tomando la perspectiva de Hessel (2011), los jóvenes, a menudo sin futuro $\mathrm{y}$ afectados por la precariedad laboral, la incertidumbre, las desigualdades más profundas y a menudo sin ofrecimientos de mejora a corto o medio plazo, han adquirido el deber de velar por la defensa de las conquistas sociales, cuidando que

nuestra sociedad sea una sociedad de la que podamos estar orgullosos: no esa sociedad de sin papeles, de expulsiones, de recelo hacia los inmigrantes; no esa sociedad que pone en duda la jubilación, el derecho a la Seguridad Social; no esa sociedad donde los medios de comunicación están en manos de la gente pudiente. (Hessel, 2011: 11).

\subsection{ENCIERROS PASADOS: OTROS ENCIERROS EN CLAVE DE REFLEXIVIDAD}

A partir de un ejercicio retrospectivo para narrar experiencias vinculadas al encierro, los y las participantes relatan vivencias a partir de un ejercicio de reflexividad en torno a sus trayectorias de vida, dando lugar y significancias al pensar encierros pasados en sus biografías. En este caso, estas experiencias están vinculadas, por un lado, a momentos bifurcativos, tales como una enfermedad o viaje, así como procesos en los que se producen cambios en los cursos de vida o al menos la evaluación de estrategias a tomar por parte de los actores (Masoaka en Muñiz-Terra, 2018: 5).

Para el caso de las experiencias ligadas a eventos particulares, los y las participantes de distintas generaciones tematizaron el encierro como momentos en que, por obligación o por vicisitud, se vieron enfrentados a estar solos física y socialmente. Tanto por la enfermedad como por viaje, los participantes de distintas generaciones describen el encierro pasado como un momento de sus 
vidas en que debieron hacer frente a situaciones de introspección debido a que no contaban con otras personas para relacionarse, los que tienen como elemento común experiencias de juventud o adolescencia:

Recuerdo que cuando tenía alrededor de 13 años me dio rubéola, que es un virus muy contagioso y muy peligroso, especialmente para embarazadas. El doctor le recomendó a mi mamá que me dejara aislada en una habitación por al menos quince días (...). La única que tenía contacto conmigo era mi madre que me llevaba la comida y me lavaba la ropa, recuerdo que estuve esos quince días en pijama. Al principio era entretenido, después ya era una tortura. (Autoentrevista pasado, participante 8 , generación adulta).

Decidí emprender un viaje en soledad por Centroamérica que duró cuatro meses (...) pasé mucho tiempo a solas, días sin interactuar genuinamente con otros y enfrentado a que todo fuera abrumadoramente nuevo. Esto me obligó a enfrentarme a mí mismo y desear el contacto con otros, desear una conversación menos superficial o al menos interactuar con gente que había conocido anteriormente. (Autoentrevista pasado, participante 9, generación intermedia).

En tanto, los participantes de la generación más joven abordaron en sus narrativas el encierro como procesos de sus trayectorias, específicamente de sus itinerarios educativos. Las vivencias de generaciones jóvenes relatadas en este artículo están referidas a los abusos de poder, esto muy vinculado a la idea de Goffman (2019[1961]) al hablar de instituciones totales y su abordaje de mecanismos de disciplinamientos ejercidos en distintas instituciones que tienen en común utilizar métodos de control, con una tendencia absorbente hacia los sujetos que están insertos en ellas.

Siguiendo a Hurtado (2004), la categoría de juventud ha estado permeada por distintos imaginarios sociales, los que van desde lo juvenil como ciclo intermedio de vida, el joven como agente de transformación social o lo juvenil desde la crisis, imaginario en el cual los jóvenes, debido a su papel como desadaptados, irresponsables e inmaduros, deben ser tratados con autoritarismo y son vistos como objetos de control. Este imaginario toma fuerza con la idea de la escuela y la escolarización chilena como una institución total. 
En el caso de los jóvenes participantes de este artículo, las trayectorias educacionales conllevaban dinámicas adultocéntricas, referidas a ellas como una matriz sociocultural y como sensibilidades dominantes y violentas (Duarte, 2012), las cuales invisibilizaban y deslegitimaban a los sujetos jóvenes por el hecho de encarnar esta categoría, a partir de imaginarios estigmatizantes:

Estaba la constante presión sobre qué estudiar al salir de cuarto medio (último año de educación obligatoria), y tomarse un año sabático no era parte del plan, debía estudiar de inmediato una vez saliera; no sabía qué estudiar, no me consideraba buena en nada; mis notas eran regulares, en el liceo que me encontraba en esos años era muy exigente, por lo que no era vista como alguien inteligente. (Autoentrevista pasado, participante 6, generación joven).

¿Por qué considero la escolaridad como encierro? Principalmente porque era el lugar en donde más sentía reprimidas mis emociones, sentires y acciones, uno de mis principales recuerdos recae en el malestar que sentía al estar ahí, cuando las inspectoras me molestaban por la falda corta pero también me llamaban la atención si ocupaba pantalones (...) el sentimiento de encierro era a la hora de educación física, en donde mi cuerpo no podía ser libre por la constante gordofobia que presentaba mi profesora de ese ramo (...) un rechazo a como ella decía el peso de cada estudiante en voz alta, decía quienes estaban en sobrepeso, obesidad y su grado. ¿Qué era lo más terrible de esto? No poder escapar. (autoentrevista pasado, participante 2 , generación joven). 


\section{A MODO CIERRE, LO QUE ESTÁ POR VENIR}

Las narrativas desarrolladas en este escrito fueron realizadas con la finalidad de explorar, en clave temporal, las experiencias de un grupo de personas de distintas generaciones, entre ellos una generación joven, una generación mayor y una generación intermedia. Las autoentrevistas construidas y analizadas en este artículo dan cuenta de las distintas reflexiones sobre lo que han significado los encierros en sus trayectorias, a partir de distintas temporalidades y promoviendo una reflexividad acerca de los propios itinerarios, vivencias y enlaces intergeneracionales, reflejados con algunos elementos de los procesos de crisis y las vivencias que estos adquieren para las distintas generaciones.

A partir de estas autoentrevistas, se compartieron distintas emociones y sensibilidades que un grupo de corte intergeneracional ha manifestado en sus narraciones: Fatiga emocional, cansancio, así como agobio, soledad, desesperanza y resignación sobre lo vivido. El malestar, el cual puede ser leído desde un plano individual, tiene resonancia con lo social, siguiendo algunas perspectivas que explican y vinculan que las movilizaciones colectivas y procesos sociopolíticos recientes vividos en Chile, tales como el estallido social, estarían vinculados a una disconformidad con el orden existente, expresados en incertidumbres futuras individuales, tales como el envejecimiento, la dificultad para pensar proyectos venideros, los anhelos de transformación social y la incertidumbre del futuro.

Por otra parte, la habituación a restricciones de movilidad y la adscripción a estrategias de autocuidado frente a la exacerbación del malestar frente al encierro han sido algunas de las experiencias vividas compartidas, vivencias con las que justamente se establece un enlace entre las diversas biografías y la colisión con los procesos sociohistóricos de crisis, en este caso debido a los recurrentes confinamientos sociales y restricciones sanitarias asociadas a la pandemia. Los proyectos truncados o transiciones de vida inesperadas son 
algunas de las inquietudes manifestadas por las y los participantes en sus experiencias de encierro y también son parte de las interrogantes por el futuro.

Estamos en un escenario de alta incertidumbre. Judt (2011) ya planteaba que, si los jóvenes de hoy están desorientados, no es por falta de objetivos. Una conversación con jóvenes produce una sorprendente lista de ansiedades e inquietudes, «una honda preocupación por el mundo que van a heredar, acompañados de una sensación general de frustración» (Judt, 2011: 19). Es que sabemos que algo va mal. Según Judt (2011), «la última vez que una cohorte de jóvenes expresó una frustración comparable ante la vaciedad de sus vidas y la desalentadora falta de sentido de su mundo fue en la década de 1920» (p. 18), aludiendo a que las generaciones pasadas no habían interiorizado en sus narrativas con tal magnitud el vivir en una era de inseguridad política, física y económica. Un siglo atrás.

Actualmente, las circunstancias se han agudizado y la crisis sociopolíticosanitaria no ha terminado. La pandemia global por SARS-CoV-2 ha pasado de ser un evento inesperado a ser parte de una perspectiva longitudinal en el tiempo, un momento bifurcativo que incidió, incide e incidirá en nuestras biografías y trayectorias futuras. La alta incertidumbre que provocan estas circunstancias, ha posicionado a los y las participantes de este artículo a preguntarse qué significa hacerse joven de la mano de estos procesos.

En las narrativas pasadas, los participantes de la generación más joven abordaron en sus narrativas el encierro como procesos vividos en sus trayectorias, específicamente, procesos que daban cuenta de su transición por la escuela. Estos relatos, tal como lo mencionamos en los puntos anteriores, estaban vinculados con la problematización de las relaciones basadas en imaginarios que abordaban a las juventudes como objetos de control, abusos de poder y expresiones adultocéntricas.

Las generaciones intermedias, en tanto, desarrollaron en parte de sus 
narrativas futuras la posibilidad de construir y sostener una sociedad distinta a la que conocemos, menos desigual. Las narrativas de esta generación intermedia apuesta por un escenario de transformación social, donde los actores sociales no están desligados de la deuda sobre el reconocimiento y la redistribución social. En este sentido, si bien la mayoría de los jóvenes ha experimentado procesos de movilidad social en sus condiciones de vida respecto a sus padres (Pérez-Roa y Ayala, 2021: 34), los y las jóvenes son conscientes de sus historias familiares, debido a que han vivido junto a sus madres, padres, abuelos y abuelas la experiencia de asfixia y agotamiento (Alé, Duarte y Miranda, 2021: 12).

Las distintas reflexiones realizadas por las nuevas generaciones están cargadas con un alto sentido crítico sobre sus propias experiencias y la realidad social. Ambas generaciones, pensando sus propias biografías, confirman que las vivencias individuales, estructuras sociales e inquietudes históricas están imbricadas, y a su vez, que las movilizaciones de los últimos años que han sido lideradas por las juventudes son disputas de largo aliento donde el futuro está en juego.

Si bien lo que está por venir es incierto, creemos que desarrollar este artículo nos hace estar mejores preparados, pues hemos abordado nuestros propios encierros en clave intergeneracional, identificando los límites y las oportunidades que con ello deviene.

RECIBIDO: 30 DE JUNIO DE 2021 ACEPTADO: 13 DE SEPTIEMBRE DE 2021 


\section{BIBLIOGRAFÍA}

Aguilera, O. (2009). Los estudios sobre juventud en Chile: Coordenadas para un estado del arte. Última Década, 31, 109-127.

Alé, S., Duarte, K. y Miranda, D. (eds.) (2021). Saltar el torniquete. Reflexiones desde las juventudes de octubre. Santiago de Chile: FCE.

APPEL, M. (2005). La entrevista autobiográfica narrativa: Fundamentos teóricos y la praxis mostrada a partir del estudio de caso sobre el cambio cultural de los Otomíes en México. Forum: Qualitative Social Research, 6(2), Art. 18. http://nbn-resolving.de/urn:nbn:de:0114-fqs0502160

Araujo, K. (ed.) (2019). Hilos tensados. Para leer el octubre chileno. Santiago de Chile: USACh.

. (2009). Habitar lo social. Santiago de Chile: LOM Ediciones.

Araujo, K. y Martuccelli, D. (2012). Desafios comunes. Retrato de la sociedad chilena y sus individuos (tomo I). Santiago de Chile: LOM Ediciones.

. (2010). La individuación y el trabajo de los individuos. Educação e Pesquisa, São Paulo, 36(n. especial), 77-91.

Auyero, J. (2013). Pacientes del Estado. Buenos Aires: EUDEBA.

Barros, V., Hauché, R., De Grandis, C. y Elgier, A. (2020). Aumento del uso de Instagram y su relación con la soledad percibida, en contexto de pandemia COVID-19. Subjetividad y Procesos Cognitivos, 24(2).

BENDIT, R. y MiRANDA, A. (2017). La gramática de la juventud: Un nuevo concepto en construcción. Última Década, 46, 4-43.

BertauX, D. (2005 [1997]). Los relatos de vida. Perspectiva etnosociológica. Barcelona: Bellaterra.

. (1999 [1980]). El enfoque biográfico, su validez metodológica, sus potencialidades. Proposiciones, 29, 52-74.

BEVERLEY, J. (2013 [1994]). Testimonio, subalternidad y autoridad narrativa. En N. K. DENZIN y Y. LiNCON (coords.), Manual de Investigación Cualitativa (Vol. 3, pp. 343-360). Barcelona: Gedisa.

Biglia, B. y Bonet-Martí, J. (2009). La construcción de narrativas como método de investigación psico-social. Prácticas de escritura compartida. 
Forum: Qualitative Social Research, 10(1), Art. 8. http://nbnresolving.de/urn:nbn:de:0114-fqs130229

BOUfOY-BASTICK, B. (2005). Auto-interviewing, Auto-ethnography and critical incident methodology for eliciting a self-conceptualised worldview. Forum: Qualitative Social Research, 5(1), Art. 37. http://nbnresolving.de/urn:nbn:de:0114-fqs0401371

Bourdieu, P. y WaCQuAnT, L. (2005 [1992]). Trasmitir un oficio. Una invitación a la sociología reflexiva. Buenos Aires: Siglo XXI.

CAnAles, M. y DuARTe, K. (2020). Imaginación sociológica para estudiar juventudes. Última Década, 54, 216-227.

CASAL, J. (2002). TVA y políticas públicas sobre juventud. Estudios de Juventud. Madrid: INJUVE.

CEA-MAdRID, J. y LÓPEZ-PISMANTE, P. (2014). Neoliberalismo y malestar social en Chile: perspectivas críticas desde la contrapsicología. Teoría y crítica de la psicología, 4, 156-169.

Cornejo, M., Besoaín, C. y Mendoza, F. (2011). Desafíos en la generación de conocimiento en la investigación social cualitativa contemporánea [94 párrafos]. Forum: Qualitative Social Research, 1. https://www.qualitativeresearch.net/index.php/fqs/article/view/1527/3140

DÁVILA LEÓN, O. (2004). Adolescencia y juventud: de las nociones a los abordajes. Última Década, 21, 83-104.

DuARTE, C. (2012). Sociedades adultocéntricas: Sobre sus orígenes y reproducción. Última Década, 36, 99-125.

. (2005). Trayectorias en la construcción de una sociología de lo juvenil en Chile. Persona y Sociedad, 19(3).

DuBET, F. (2011). La experiencia sociológica. Barcelona: Gedisa.

Ellis, C., AdAms, T. y Bochner, A. (2011). Autoethnography: An overview. Forum: Qualitative Social Research, 12(1), Art. 10. http://nbnresolving.de/urn:nbn:de:0114-fqs1101108

FARo Digital (12 de julio de 2020). «El siglo XXI acaba de comenzar con la pandemia del Covid». Boaventura de Sousa Santos \#charlascovid [Archivo de Video]. Youtube. https://youtu.be/yiE-skBrMlM 
Galaz, C. y Rubilar, G. (2019). Experiencias profesionales en intervención psicosocial: el ejercicio narrativo como metodología de reflexividad y vigilancia epistemológica. Revista Latinoamericana de Metodología de las Ciencias Sociales, 9(1). https://doi.org/10.24215/18537863e050

GARCÉS, M. (2012). El despertar de la sociedad. Los movimientos sociales de América Latina y Chile. Santiago de Chile: LOM Ediciones.

GARZÓn, B. (2011). Reaccionar para avanzar. En R. M. ARTAL (ed.), Reacciona (pp. 45-61). Madrid: Santillana.

GofFMAN, E. (2019 [1961]). Internados. Ensayos sobre la situación social de los enfermos mentales. Buenos Aires: Amorrortu.

GonZÁlez, G. (2020). Apuntes para el estudio de la salud mental en Chile actual. Revista Electrónica de Estudios Latinoamericanos, 18(1), 25-43.

HESSEL, E. (2011). ;Indignaos! Un alegato contra la indiferencia y a favor de la insurrección pacífica. Barcelona: Destino.

Hurtado, R. (2004). Reflexiones sobre la Teoría de Imaginarios. Revista de Epistemología de las Ciencias Sociales, Cinta moebio (21), 169-174.

JACINTO, C. (2016). Presentación: Educación y trabajo en tiempos de transiciones inciertas. Páginas de Educación, 9(2), 1-13.

Johnson, M.C., SAletti-Cuesta, L. y Tumas, N. (2020) Emociones, preocupaciones y reflexiones frente a la pandemia del COVID-19 en Argentina. Ciênc. saúde coletiva, 25 (suppl 1). https://doi.org/10.1590/1413-81232020256.1.10472020

JUDT, T. (2011). Algo va mal. Madrid: Taurus.

LECCARDI, C. y FEIXA, C. (2011). El concepto de generación en las teorías sobre la juventud. Última Década, 34, 11-32.

MANnheim, K. (1993 [1928]). El problema de las generaciones. Revista Española de Investigaciones Sociológicas, 62.

Marsal, J. F. (1979). Pensar bajo el franquismo. Intelectuales y política en la generación de los años cincuenta. Barcelona: Península.

MARTUCCELLI, D. (2017). La nueva dinámica de la condición social moderna. Revista de Sociología, 32(1), 89-105. doi: 10.5354/0719529x.2017.47887 
. (2015). Les deux voies de la notion d'épreuve en sociologie. Sociologie, 6, 43-60.

Millenaar, V., Dursi, C., Garino, D., Roberti, E., Burgos, A., Sosa, M. y JACINTO, C. (2016). Los jóvenes en la construcción: dinámicas y actores en dispositivos de educación-formación-empleo. Última Década, 24(45), 10-33. https://dx.doi.org/10.4067/S0718-22362016000200002

Mills, Ch. W. (2005 [1959]). Apéndice. Sobre artesanía intelectual. En Ch. W. MiLls, La imaginación sociológica (pp. 206-236). Ciudad de México: FCE.

MirandA, A. (2016). Transiciones juveniles, generaciones sociales y procesos de inclusión social en Argentina post-neoliberal. Linhas Críticas, 22(47), 130-149.

MuÑIZ-TERRA, L. (2018). El análisis de acontecimientos biográficos y momentos bifurcativos: una propuesta metodológica para analizar relatos de vida. Forum: Qualitative Social Research, 19(13), 1-25. En Memoria Académica. Disponible en: http://www.memoria.fahce.unlp.edu.ar/art_revistas/pr.8579/pr.8579.pdf

MuÑIz Terra, L. y RoBerti, E. (2018). Las tramas de la desigualdad social desde una perspectiva comparada: hacia una reconstrucción de las trayectorias laborales de jóvenes de clases medias y trabajadora. Estudios del Trabajo. Revista de la Asociación Argentina de Especialistas en Estudios del Trabajo (ASET), https://aset.org.ar/ojs/revista/article/view/19

Ortega GonzÁlez, D. (2018). Envejecimiento y trato hacia las personas mayores en Chile: una ruta de la desigualdad persistente. Sophia Austral, (22), 223-246. https://dx.doi.org/10.4067/S0719-56052018000200223

PAIS, J. M. (2002). Laberintos de vida: paro juvenil y rutas de salida (jóvenes portugueses). Estudios de Juventud, 56.

PÉRez-RoA, L. y Ayala, C. (2021). Las precariedades económicas de los «privilegiados»: Morosidad en jóvenes profesionales de Santiago y Concepción. En S. Alé, K. Duarte, y D. Miranda (eds.), Saltar el torniquete. Reflexiones desde las juventudes de octubre. (pp. 29-35). Santiago de Chile: FCE.

PINTO, J. (2020). La imagen del encierro. Artefacto visual, revista de estudios visuales latinoamericanos, 9, 29-35.

Piovani, J. y MuÑIZ-TERRA, L. (coods.) (2018). ¿Condenados a la reflexividad? 
Apuntes para repensar el proceso de Investigación Social. Buenos Aires: CLACSO.

Rivera VArgas, P. y PAsserón, E. (2020). Ser joven en el confinamiento: «¡De la escuela extrañamos todo!». Revista Mexicana de bachillerato a distancia, 24, 1-9.

Rodríguez Quiroga de Pereira, A., Bongiardino, L., Borensztein, L. y VÁzQUEZ, N. (2020). Sentimientos de soledad y problemas internalizantes frente al distanciamiento social y confinamiento preventivo por el coronavirus COVID-19. Subjetividad y Procesos Cognitivos, 24(2), 57-84.

Rubilar, G. (2015). Prácticas de memoria y construcción de testimonios de investigación. Reflexiones metodológicas sobre autoentrevista, testimonios y narrativas de investigación de trabajadores sociales [112 párrafos]. Forum: Qualitative Social Research, 16(3), Art. 3. http: //nbnresolving.de/urn:nbn:de:0114-fqs150339

(2013). Repertorios y aproximaciones biográfico-narrativas. Testimonios y análisis de prácticas investigativas en trabajadores sociales. Forum: Qualitative Social Research, 14(2), Art. 27. http://nbnresolving.de/urn:nbn:de:0114-fqs130229.

Rubilar, G., Muñiz-Terra, L. y Domínguez, M. (2019). Sobre el futuro. Discursos y prácticas laborales de estudiantes de liceos técnicoprofesionales en tres claves de desigualdad. Psicoperspectivas, 18(3). doi: 10.5027/psicoperspectivas-vol18-issue3-fulltext-1656

Rubilar, G., Santibáñez, C. y Echeverría, V. (2020). Tiempos crítico. Análisis de la relación entre violencia y personas en situación de calle en contextos de «normalidad»y «excepción». Cuadernos Médico Sociales, 60(2), 23-37.

Thunberg, G. (2020). Cambiemos el mundo. Madrid: Penguin Random.

Trabajo Social PUCV (25 de junio de 2021). Seminario Trayectorias y desafíos de la formación para el trabajo. Conferencia Leandro Sepúlveda y Telmo Caria. [Archivo de Video]. Facebook. https://www.facebook.com/403774433150705/videos/79737862783676 2

VAlles, M. y BAER, A. (2005). Investigación social cualitativa en España: Pasado, presente y futuro. Un retrato. Forum: Qualitative Social Research, 6(3), Art. 18, http://nbn-resolving.de/urn:nbn:de:0114fqs 0503183 